\title{
Antiviral Activity of Zinc Oxide Nanoparticles Mediated by Plumbago indica L. Extract Against Herpes Simplex Virus Type I (HSV-I)
}

\author{
Mina Michael Melk $\mathbb{D}^{\prime}$ \\ Seham S El-Hawary (D) \\ Farouk Rasmy Melek (iD ${ }^{2}$ \\ Dalia Osama Saleh (1D ${ }^{3}$ \\ Omar M Ali (iD ${ }^{4}$ \\ Mohamed A El Raey $\mathbb{D D}^{5}$ \\ Nabil Mohamed Selim (D) \\ 'Pharmacognosy Department, Faculty of \\ Pharmacy, Cairo University, Giza, Egypt; \\ ${ }^{2}$ Chemistry of Natural Compounds \\ Department, National Research Centre, \\ Giza, Egypt; ${ }^{3}$ Pharmacology Department, \\ National Research Centre, Giza, Egypt; \\ ${ }^{4}$ Department of Chemistry, Turabah \\ University College, Turabah Branch, Taif \\ University, Taif, 21944, Saudi Arabia; \\ ${ }^{5}$ Department of Phytochemistry and \\ Plant Systematics, Pharmaceutical \\ Division, National Research Centre, \\ Dokki, Cairo, Egypt
}

Correspondence: Nabil Mohamed Selim; Omar M Ali

Email nabil.selim@pharma.cu.edu.eg; om.ali@tu.edu.sa
Introduction: Plumbago indica L. is considered a valuable source in the Plumbaginaceae family for various types of active compound such as alkaloids, phenolics and saponins. To promote the usage of $P$. indica in the bionanotechnology field, zinc oxide nanoparticles (ZnONPs) were biosynthesized by using its alcoholic extract. The inhibitory effects of ZnONPs and the plant extract were also evaluated against HSV-1.

Methods: ZnONPs were described by the following techniques, UV-visible spectroscopy, Fourier transform infrared spectroscopy (FTIR), dynamic light scattering (DLS), zeta potential, scanning electron microscopy (SEM), transmission electron microscopy (TEM) and x-ray diffraction (XRD). The phenolic and flavonoid contents of $P$. indica extract, which are accountable for bioreduction, formation and stabilization of the nanoparticles, were analyzed by HPLC technique. The antiviral assessment was implemented on both agents by using Vero cell lines.

Results: DLS revealed that the average size of ZnONPs was $32.58 \pm 7.98 \mathrm{~nm}$ and the zeta potential was $-20.8 \mathrm{mV}$. The observation of TEM analysis revealed that the particle size of ZnONPs varied from 2.56 to $8.83 \mathrm{~nm}$. The XRD analysis verified the existence of pure crystals of hexagonal shapes of nanoparticles of $\mathrm{ZnO}$ with a main average size of $35.28 \mathrm{~nm}$ that is approximating to the values of particle size acquired by SEM analysis (19.64 and $23.21 \mathrm{~nm}$ ). The HPLC analysis of $P$. indica ethanolic extract showed that gallic acid, chlorogenic acid and rutin were the major compounds, with concentrations equal to 8203.99, 2965.95 and $1144.99 \mu \mathrm{g} / \mathrm{g}$, respectively. Regarding the antiviral assessment, the synthesized uncalcinated $\mathrm{ZnONPs}$ were found to exhibit a promising activity against HSV-1, with $\mathrm{CC}_{50}$ and $\mathrm{IC}_{50}$ values equal to $43.96 \pm 1.39$ and $23.17 \pm 2.29 \mu \mathrm{g} / \mathrm{mL}$, respectively.

Conclusion: The green synthesized ZnONPs are considered promising adjuvants to enhance the efficacy of HSV-1 drugs.

Keywords: $\mathrm{ZnO}$ nanoparticles, Plumbago indica L., HPLC analysis, antiviral activity and green synthesis

\section{Introduction}

The nanoparticles of metal oxide possess valuable physical, chemical, and biological properties and are considered a promising tool used in various applications. ${ }^{1}$ In the process of nanoparticle synthetization, numerous side effects are arising due to the usage of toxic chemicals acting as reductive and capping agents. However, the utilization of numerous natural extracts, particularly plant extracts, in the metal oxide nanoparticles synthesis has received attention. This is because the natural approach is time saving and ecofriendly compared to the other conventional methods; also, the occurrence of several bioactive phytochemicals assists in the 
reduction and stabilization of nanomaterials. ${ }^{2}$ Recently, scientists have recognized the importance of zinc oxide $(\mathrm{ZnO})$ due to its plentiful applications and unique properties. $^{3-6}$ The nanoparticles containing $\mathrm{ZnO}$ have an important role in avoidance of the aquatic and dependent ecosystem imbalances arising from organic contaminants such as dye fragments. ZnONPs synthesized by Artocarpus heterophyllus leaves were effective in degradation of Congored dye. ${ }^{7} \mathrm{ZnO}$ nanorods produced by Calotropis gigantea were proved to act as a photo catalyst in the degradation process of titan yellow dye. ${ }^{8}$ Also, the ZnONPs application at concentration of $100 \mu \mathrm{g} \mathrm{mL}$ protects plants from tobacco mosaic virus infection. ${ }^{9}$

Reviewing previous reports, ZnONPs were successfully synthesized from numerous natural extracts as Aloe vera ${ }^{10}$ Passiflora caerulea ${ }^{11}$ and Azadirachta indica. ${ }^{12,13}$ Furthermore, ZnONPs have received much attention and are presently applied in numerous fields such as packaging and food additives. Among other types of nanoparticle, ZnONPs become absorbed easily by the biological tissues and have a good biocompatibility with human cells more than zinc metal. Additionally, ZnONPs demonstrate an antiviral activity against many viruses such as various types of respiratory viruses and herpes viruses, including SARS-CoV-2. ${ }^{14}$ There are several mechanisms for the antiviral activity of ZnONPs, such as prevention of viral entry, viral replication and spreading to organs, which can eventually trigger reactive oxygen species leading to oxidative injury and viral death. ${ }^{14}$ Zinc containing compounds revealed antiviral activity against numerous viruses by different mechanisms such as physical processes including attachment to virus, inhibition of virus infection, and uncoating. Also, these compounds showed activity by biological mechanisms such as inhibition of viral polymerases and protease enzymes. ${ }^{9}$

Generally, $\mathrm{Zn}$ is an important component that occurs in human tissue such as the bone, brain, muscle and skin. This vital element is also involved in various enzyme processes such as metabolism and protein and nucleic acid biosynthesis. ${ }^{15}$

It is worth noting that the US Food and Drug Administration (FDA) categorized $\mathrm{ZnO}$ as a nontoxic substance. Therefore, ZnONPs are allowed to be applied in numerous biomedical activities. ZnONPs are characterized by their low toxicity and cost effectiveness and therefore can be applied in numerous therapeutic fields, such as wound healing and drug delivery, and for anticancer, antidiabetic, antibacterial and anti-inflammatory purposes. ${ }^{15}$
Plumbago indica L. belongs to the largest genus of flowering plant in the family Plumbaginaceae. This plant, previously known as $P$. rosea, can grow in diverse regions of Southeast Asia, Europe, Malaysia, Indonesia, Africa, China and India. ${ }^{16} P$. indica contains various types of constituent, such as apigenin, kaempferol, luteolin, plumbaginol, myricetin tetra methyl ether, ampelopsin tetramethylether, Plumbagin-5-O- $\alpha$-L-Rhamnopyranoside, campesterol, $\beta$-sitosterol and stigmasterol. ${ }^{17,18}$ Among numerous Plumbago species, $P$. indica contains a high amount of plumbagin. ${ }^{19}$ Numerous pharmacological activities for plumbagin were reported, such as antioxidant, ${ }^{20}$ antimicrobial, ${ }^{21}$ and anticancer ${ }^{22}$ activities.

The interactions between nanoparticles and biological targets have revolutionized the field of drug development. ${ }^{23}$ Selenium NPs play important roles in various medical applications such as anticancer, antitumor, antibacterial and antiviral agents. They boost drug and gene delivery and show synergistic properties. ${ }^{24}$ The micro and nano $\mathrm{ZnO}$ particles exhibit highly promising prophylactic agents against HSV-1 ${ }^{25}$ and PEGylation of these nanoparticles causes reduction of the cytotoxic effect and enhances their antiviral efficacy. ${ }^{26}$ Numerous metal NPs were successfully ecofriendly synthesized by different Plumbago species and found to have various biological activities. Sliver NPs were previously green-synthesized using various Plumbago species such as $P$. indica, P. auriculata, and P. zeylanica and proved to possess antioxidant, antitumor, antibacterial, larvicidal and antitubercular properties. ${ }^{27-30}$ P. zeylanica was used to synthesize selenium, copper, silver, gold, and bimetallic (silver and gold) NPs. These nanoparticles were found to exhibit antioxidant, antibacterial, ${ }^{31}$ antidiabetic, ${ }^{32}$ antimicrobial and antibiofilm effects. ${ }^{33}$ Highly stable ZnONPs were also obtained from $P$. zeylanica extract and were found to have antibacterial activity against Staphylococcus aureus and Salmonella typhimurium. ${ }^{34} \mathrm{ZnONPs}$ synthesized from $P$. auriculata alcoholic extract demonstrated an antiviral effect against avian metapneumovirus subtype B. ${ }^{35}$

Most of the investigations done on the antimicrobial activity of ZnONPs focused on the antibacterial effects and there are limited studies dealing with interaction between ZnONPs or $P$. indica extract and viruses.

The current study aimed to inspect the effect of ZnONPs produced by alcoholic extract of $P$. indica against HSV-1. Furthermore, the phytochemical constituents present in this extract are characterized by HPLC technique. 


\section{Materials and Methods}

\section{Plant Material}

Flowering aerial parts of $P$. indica were procured from EL -MAZHAR botanical garden, Giza, Egypt. The plant was kindly authenticated by Engineering Therease Labib Consultant for plant identification at El-Orman botanical garden, Giza and Dr. Mohamed El Gebaly, Botany Taxonomist at National Research Centre Herbarium, Dokki, Giza. Voucher specimen (numbered 19062020) was reserved at the herbarium of the Department of Pharmacognosy, Faculty of Pharmacy, Cairo University. $P$. indica flowering aerial parts were air-dried, coarsely powdered and preserved in tightly closed amber-colored glass containers at room temperature. This research was performed in accordance with the guidelines of occupational health and safety committee at National Research Centre, Giza, Egypt and accepted by scientific research ethics committee of Faculty of Pharmacy, Cairo University, Giza, Egypt.

\section{Extraction of Plant Active Ingredients}

The air-dried powder of the flowering aerial parts of $P$. indica $(100 \mathrm{~g})$ were successfully extracted by maceration technique with $90 \%$ ethanol $(250 \mathrm{~mL} . \times 3)$. The obtained extract was evaporated using Buchi Rotary Evaporators under reduced pressure till dryness $(2.5 \mathrm{~g}$.).

\section{HPLC Analysis}

HPLC analysis was performed by means of an Agilent 1260 series. The separation column was Eclipse C18 column (4.6 $\mathrm{mm} \times 250 \mathrm{~mm}$ i.d., $5 \mu \mathrm{m}$ ). The mobile phase was comprised of (A) water and (B) $0.05 \%$ trifluoroacetic acid in acetonitrile using a flow rate of $1 \mathrm{~mL} / \mathrm{min}$. The mobile phase was automatic flow in a linear gradient as follows: 0 $\min (82 \% \mathrm{~A}$ and $18 \% \mathrm{~B}) ; 0-5 \min (80 \% \mathrm{~A}$ and $20 \% \mathrm{~B}) ; 5-12$ $\min (60 \% \mathrm{~A}$ and $40 \% \mathrm{~B})$ and $12-16 \min (82 \% \mathrm{~A}$ and $18 \%$ B). The detector used was multi-wavelength and adjusted at $280 \mathrm{~nm}$. The injection volume was $10 \mu \mathrm{L}$ for the standard and extract solutions. The column temperature was set at $35^{\circ} \mathrm{C}$.

\section{Green Synthesis of Zinc Oxide Nanoparticles}

ZnONPs were synthesized from the alcoholic extract of the flowering aerial parts of $P$. indica by a method illustrated previously by Attia et al, ${ }^{36}$ with slight modification in which $P$. indica. dried extract $(1 \mathrm{~g})$ was dissolved in ethanol $(100 \mathrm{~mL})$ reacted with zinc acetate $(10 \mathrm{~g})$ dissolved in doubly distilled water $(1000 \mathrm{~mL})$ and heated in water bath for $20 \mathrm{~min}$ at $100{ }^{\circ} \mathrm{C}$. Ammonium hydroxide (a few drops) was added to the reactant media to maintain $\mathrm{pH}$ at 12 , in which $\mathrm{ZnONPs}$ precipitate is created. The mixture was set for 60 minutes for complete reduction of zinc acetate to ZnONPs. The obtained ZnONPs was centrifuged at $4000 \mathrm{rpm}$, followed by washing in bi-distilled water (twice) and ethanol (twice) to yield white pellets of nanoparticles upon freeze drying.

\section{Characterization of Metal Nanoparticles}

The ZnONPs were initially analyzed by means of UV1601 (Shimadzu Corporation, Japan) UV-visible spectroscopy ranging between 200 and $600 \mathrm{~nm}$. Then, FTIR analysis using attenuated total reflectance mode by a Jasco FTIR 4100 spectrophotometer (Japan) was applied to categorize the functional groups and various phytochemical compounds responsible for formation and stabilization of the nanoparticles. Dynamic light scattering (DLS) analysis obtained by a Zetasizer (HT Laser, ZEN3600, Malvern Instruments, Malvern, UK) was applied to investigate particle size and zeta potential of the nanoparticles. Morphology and particle size of ZnONPs mediated by $P$. indica extract was determined by TEM (JEOL-JEM-1011, Japan) and FE-SEM (Mira3 Tescan). A few drops from the suspension of $\mathrm{ZnO}$ nanoparticles were applied to a carbon-coated copper grid and the solvent was evaporated at room temperature prior to recording the images. The powdered sample was also subjected to $\mathrm{CuK} \alpha 1-\mathrm{X}$ Ray diffractometer radiation $(\lambda=$ $1.5406 \mathrm{~A}^{\circ}$ ) operating at $40 \mathrm{kV}$ and $30 \mathrm{~mA}$ with $2 \theta$ ranging from $20-90^{\circ}$ to verify the occurrence of $\mathrm{ZnO}$ crystals and define their structure and size.

\section{Evaluation of the Antiviral Activity of ZnONPs and $P$. indica}

The antiviral assessment of ZnONPs and $P$. indica extract was performed by plaque inhibition assay using Vero cells (ATCC, Manassas, VA, USA) acquired from the kidneys of African green monkey, Herpes Simplex Virus type 1 (EA2387, Hopital PitiéSalpétrière, France) and acyclovir as standard reference drug. The proliferation of the Vero cells line and the preparation of the virus stock were performed according to El-Toumy et $\mathrm{al}^{37}$ and stored at $-70^{\circ} \mathrm{C}$ until used. Virus titrations were calculated from cytopathogenicity and directly related to the $50 \%$ of 
infectious doses per milliliter $\left(2 \times 10^{7.4} \mathrm{ID}_{50} / \mathrm{mL}\right)$ according to the Reed and Muench dilution method. ${ }^{38}$

\section{Cytotoxicity Assay}

The cytotoxicity of the investigated agents was assessed by neutral red dye-uptake technique as previously reported. ${ }^{39}$ Briefly, the test compounds and acyclovir were diluted in $0.1 \%$ dimethyl sulfoxide (DMSO). Stock solutions at a concentration of $200 \mu \mathrm{g} / \mathrm{mL}$ were prepared by $0.1 \%$ DMSO. Vero cell monolayers cultivated with investigated agents or the positive control (two-fold serial dilutions each) were incubated for $72 \mathrm{~h}$ at $37{ }^{\circ} \mathrm{C}$ in $5 \% \mathrm{CO}_{2}$ using Eagle's MEM containing 8\% FCS. After incubation, the alterations in cellular morphology were visualized by means of an inverted optical microscope for determination of MNTC (maximum non-toxic concentrations). The CC50 values (concentrations of each agent essential for reduction of cell viability by $50 \%$ ) were computed by comparing with the untreated cells. The cytotoxicity of compounds active against HSV-1 was also assessed in triplicate to obtain statistically relevant data for final calculations.

\section{Anti-herpes Simplex Virus Type I (HSV-I) Assay}

Each well in a 96-well plate containing Vero cellular suspension $\left(100 \mu \mathrm{L}, 3.5 \times 10^{5}\right.$ cells $\left./ \mathrm{mL}\right)$ and investigated agents $(50 \mu \mathrm{L})$ was infected with viral suspension $(50 \mu \mathrm{L})$ at MOI (multiplicity of infection) of $0.001 \mathrm{ID}_{50} /$ cells. The plate was then incubated for 3 days at $37^{\circ} \mathrm{C}$ in $5 \% \mathrm{CO}_{2}$ without changing the media. Blanks for virus and cell were run simultaneously. After the viral growth, the cultures were stained with neutral red dye $(50 \mu \mathrm{L}, 0.15 \%$ in saline, $\mathrm{pH}$ 5.5) and incubated for $45 \mathrm{~min}$ at $37^{\circ} \mathrm{C} .{ }^{40}$ Phosphate buffered saline ( $\mathrm{pH}$ 7.2) was used for removing excess dye while the elution of the dye attached in the viable cells was performed using citrate ethanol buffer $(100 \mu \mathrm{L} /$ well). The anti-herpetic compound acyclovir was used with concentrations ranging from 0.5 to $5 \mu \mathrm{g} / \mathrm{mL}$. The cell culture monolayer was completely destroyed after shaking the plate for $20 \mathrm{~min}$. The absorbance (OD) of each well was recorded using a multichannel spectrophotometer at $540 \mathrm{~nm}$. The OD was directly proportional to the percentages of viable cells that were inversely related to the cytopathic effect (CPE) ratio. The values of $\mathrm{CC}_{50}$ and $\mathrm{IC}_{50}$ of all the investigated agents were computed from the regression straight line of each assay that was obtained on the basis of virus controls (100\% CPE) and cell controls $(0 \% \mathrm{CPE}) .{ }^{41}$ The percentage of protection $(\% \mathrm{P})$ was calculated by the following formula: (no\% $\mathrm{P}=[(\mathrm{A} 1)-$ $(\mathrm{A} 2)] /[(\mathrm{A} 3)-(\mathrm{A} 2)] \times 100)$ where $(\mathrm{A} 1)$ is the absorbance of the test sample, (A2) is the absorbance of the virusinfected control and (A3) is the absorbance of the mockinfected control. The ratio of (A2) to (A3) is expressed as "\% of control".

\section{Statistical Analysis}

GraphPad PRISM software V.5 was used for calculations and statistical analysis. The values of mean and standard deviations (SDs) for each experiment were calculated. ANOVA followed by Tukey's multiple comparison test was used to obtained the significance between the tested agents and the positive control.

\section{Results and Discussion HPLC Analysis of Phenolic Compounds}

HPLC analysis (Figure 1) revealed the occurrence of 15 compounds in the alcoholic extract of the aerial parts of $P$. indica. The HPLC analysis of this extract showed that gallic acid, chlorogenic acid and rutin were the major compounds, with concentrations equal to 8203.99, 2965.95 and $1144.99 \mu \mathrm{g} / \mathrm{g}$, respectively (Table 1). The rest of the compounds were characterized as catechin, methyl gallate, caffeic acid, syringic acid, rutin, ellagic acid, coumaric acid, vanillin, ferulic acid, naringenin, taxifolin and cinnamic acid and are reported here for the first time. Kaempferol was previously reported as kaempferol3-O-rhamnoside from $P$. indica $\mathrm{L}$. flowers. ${ }^{42}$ To the best of our knowledge, this is the first approach for identification of phenolic compounds using the HPLC technique.

\section{ZnO Nanoparticle Formation}

$P$. indica $\mathrm{L}$. alcoholic extract reacted with zinc acetate solution in hot water bath at $80^{\circ} \mathrm{C}$. Addition of ammonium hydroxide to the reaction mixture precipitated $\mathrm{ZnONPs}$ (Figure 2). ${ }^{36}$

\section{ZnONPs Characterizations UV Analysis}

A maximum absorption peak of $\mathrm{ZnONPs}$ synthesized from P. indica extract was found at $368 \mathrm{~nm}$ (Figure 3), indicating the ZnONPs formation. ${ }^{43}$ The broadness of absorption could be attributed to the transition of the electronic cloud on the overall skeleton of the ZnONPs. ${ }^{44}$ At a nano scale, $\mathrm{ZnO}$ has 

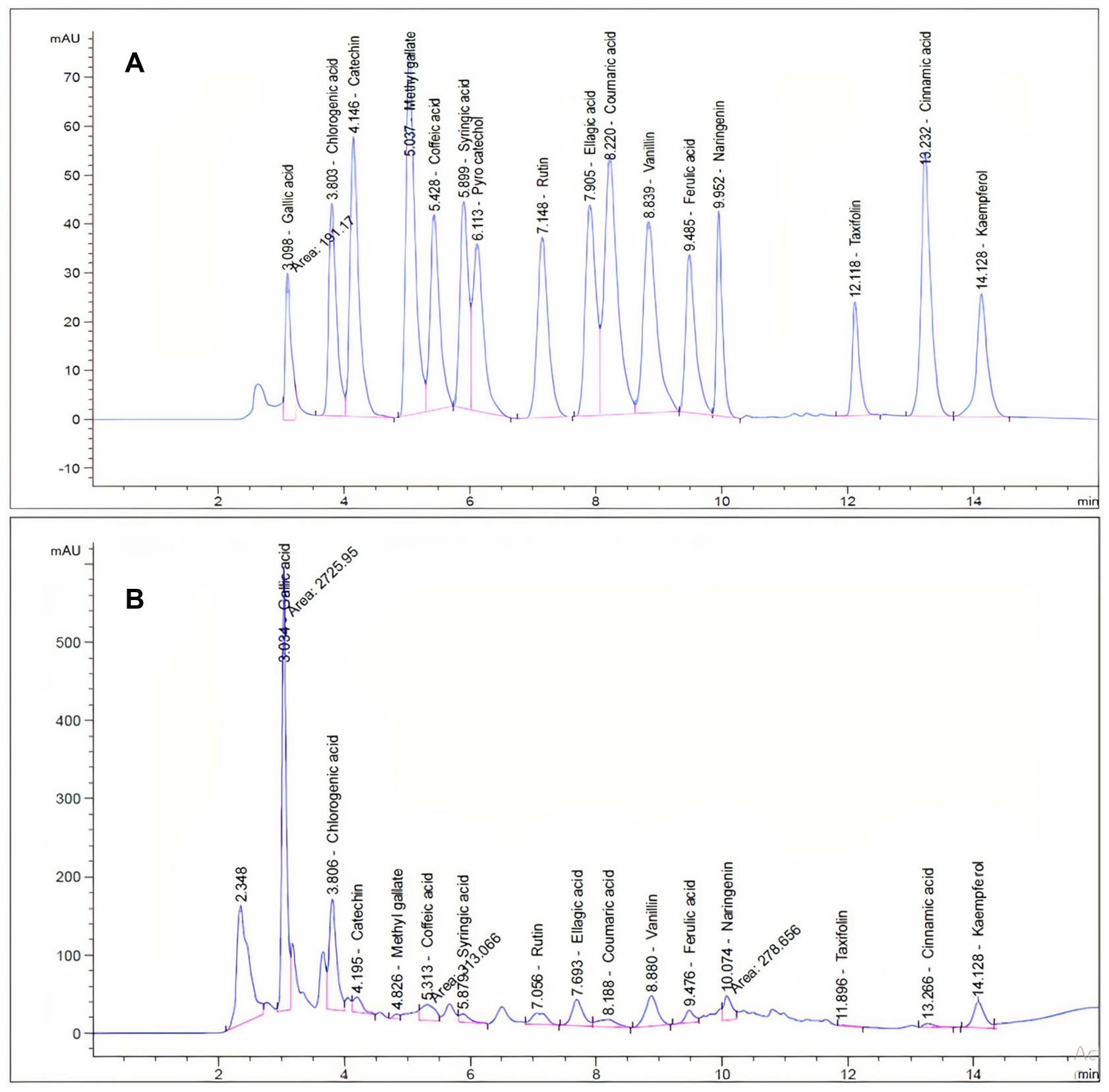

Figure I HPLC chromatogram: (A) standard mixture of polyphenolic compounds; (B) ethanolic extract of $P$. indica aerial parts.

shorter wavelengths than those found in standard $\mathrm{ZnO}$, which is in parallel with the studies supporting the shorter wavelengths of material oxides. ${ }^{45,46}$ The absorption of the ZnONPs in the UV region proves that the nanoparticles could be incorporated in various medical applications such as antiseptic ointments or sunscreen protectors. ${ }^{47}$

\section{FT-IR Analysis of ZnONPs and P. indica L}

The FTIR was analyzed in the range of 400 to $4000 \mathrm{~cm}^{-1}$ to identify the different functional groups present in the nanoparticles and $P$. indica extract. Regarding ZnONPs
(Figure 4A), an intense absorption peak at $3457 \mathrm{~cm}^{-1}$ indicated the presence of the $\mathrm{OH}$ group responsible for the water adsorption on the ZnONP surface. Bands observed at 2925 and $2859 \mathrm{~cm}^{-1}$ related to the stretching vibration while the band existing at $913 \mathrm{~cm}^{-1}$ was assigned to the bending vibration of alkane groups. Absorption peaked at $1084 \mathrm{~cm}^{-1}$ signifying the occurrence of $\mathrm{CO}$ group of ethers, carboxylic acid esters and alcohols. The representative peaks of the ZnONPs were assigned at 524 and $493 \mathrm{~cm}^{-1}$. FTIR spectrum for $P$. indica extract (Figure 4B) displayed a significant 
Table I Polyphenolic Compounds of P. Indica L. Aerial Parts Identified by HPLC

\begin{tabular}{|c|c|c|c|c|c|}
\hline No. & Compound & $\mathbf{R} \mathbf{T}^{*}$ & RRT* & Area & Conc. $(\mu g / g)$ \\
\hline 1 & Gallic acid & 3.034 & 0.43 & 2725.95 & 8203.99 \\
\hline 2 & Chlorogenic acid & 3.806 & 0.54 & 1159.31 & 2965.95 \\
\hline 3 & Catechin & 4.195 & 0.59 & 193.11 & 792.42 \\
\hline 4 & Methyl gallate & 4.826 & 0.68 & 36.21 & 16.83 \\
\hline 5 & Coffeic acid & 5.313 & 0.75 & 313.07 & 458.24 \\
\hline 6 & Syringic acid & 5.879 & 0.83 & 120.66 & 180.82 \\
\hline 7 & Rutin & 7.056 & 1.00 & 245.62 & 1144.99 \\
\hline 8 & Ellagic acid & 7.693 & 1.09 & 404.02 & 925.77 \\
\hline 9 & Coumaric acid & 8.188 & 1.16 & 192.09 & 111.81 \\
\hline 10 & Vanillin & 8.88 & 1.26 & 508.81 & 391.65 \\
\hline II & Ferulic acid & 9.476 & 1.34 & 154.96 & 185.20 \\
\hline 12 & Naringenin & 10.074 & 1.43 & 278.66 & 527.48 \\
\hline 13 & Taxifolin & 11.896 & 1.69 & 9.87 & 24.58 \\
\hline 14 & Cinnamic acid & 13.266 & 1.88 & 66.36 & 22.94 \\
\hline 15 & Kaempferol & 14.128 & 2.00 & 404.00 & 542.65 \\
\hline
\end{tabular}

Abbreviations: ${ }^{\mathrm{R} T}$, retention time; RRT, relative retention time to rutin.

peak at $3317 \mathrm{~cm}^{-1}$, indicating the existence of phenolic or alcoholic $\mathrm{OH}$ groups. Medium bands observed at 2931 and $2830 \mathrm{~cm}^{-} 1$ revealed the incidence of alkane groups. The noticeable peaks at 1623,1391 and $1334 \mathrm{~cm}^{-1}$ in the alcoholic extract indicated the existence of cyclic $\mathrm{C}-\mathrm{C}$ or $\mathrm{C}=\mathrm{O}$ stretch of polyphenolic compounds shifted to $1609 \mathrm{~cm}^{-1}$ in ZnONPs as a result of the bond between the polyphenols and NPs. The intense peak acquired at $1019 \mathrm{~cm}^{-1}$ proved the presence of alkane groups. The moderate bond that appeared at $730 \mathrm{~cm}^{-1}$ and the weak peaks at $894 \mathrm{~cm}^{-1}$ represented the alkenes $(=\mathrm{C}-\mathrm{H})$ group. ${ }^{5,48}$

\section{Dynamic Light Scattering and Zeta Potential}

The size distribution image (DLS) of green synthesized form of $\mathrm{ZnONPs}$ is shown in Figure 5A. The detected distribution of ZnONPs size varied from 15 to $94 \mathrm{~nm}$. This nanoparticle's estimated average particle size distribution was $32.58 \pm 7.98 \mathrm{~nm}$. The stability of ZnONPs can be estimated by the zeta potential value. ZnONPs can be confirmed as stable colloidal solution when the absolute zeta potential is more than $30 \mathrm{mV}^{49}$ The value of ZnONPs' zeta potential produced by $P$. indica was demonstrated as a clear peak at $-20.8 \mathrm{mV}$ (Figure 5B), signifying that the biosynthesized ZnONPs were negatively charged and moderately distributed in the medium.

Transmission Electron Microscope (TEM) and Scanning Electron Microscopy (SEM) Analyses

Low and high resolution transmission electron microscope (TEM) analysis showed the existence of ZnONPs in hexagonal shape and their corresponding range of particle size was between 2.56 and $8.83 \mathrm{~nm}$ (Figure 6A). The surface morphology of the obtained ZnONPs was visualized by scanning electron microscopy (SEM). The obtained image showed that most $\mathrm{ZnONPs}$ varied from spherical to hexagonal, with the particle diameter ranging from 19.64 to $23.21 \mathrm{~nm}$ (Figure 6B). SEM analysis illustrated the morphology and size of ZnONPs that was dispersed moderately in the medium. The relatively larger sizes observed by SEM were due to the smaller nanoparticle agglomeration.

\section{XRD Analysis}

The investigation of the structural features of ZnONPs was established through X-ray diffraction (XRD) (Figure 7). ZnONPs mediated by $P$. indica extract presented peaks with $2 \theta$ values recognized at $31.799^{\circ}, 34.448^{\circ}, 36.271^{\circ}, 47.581^{\circ}$, $56.641^{\circ}, 62.902^{\circ}, 67.981^{\circ}, 68.98^{\circ}$, and $72.751^{\circ}$ corresponding to (100), (002), (101), (102), (110), (103), (200), (112), (201), 

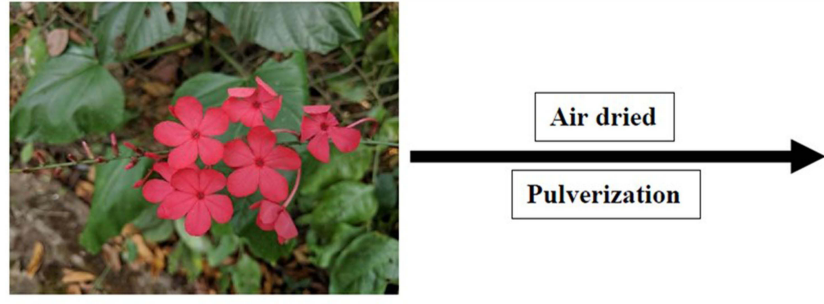

Plumbago indica $\mathrm{L}$.

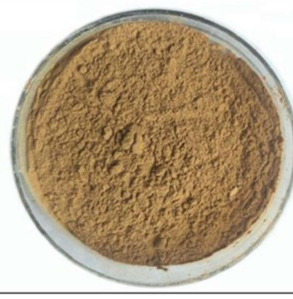

Dried and pulverized aerial parts
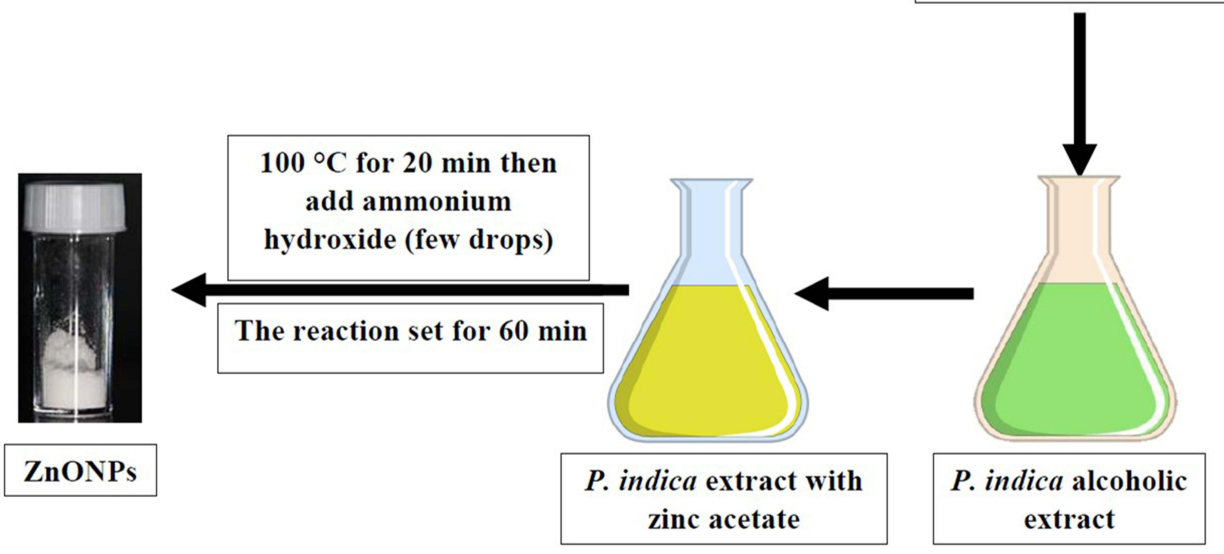

Figure 2 Schematic demonstration for the green synthesized ZnONPs mediated by the alcoholic extract of the aerial parts of $P$. indica.

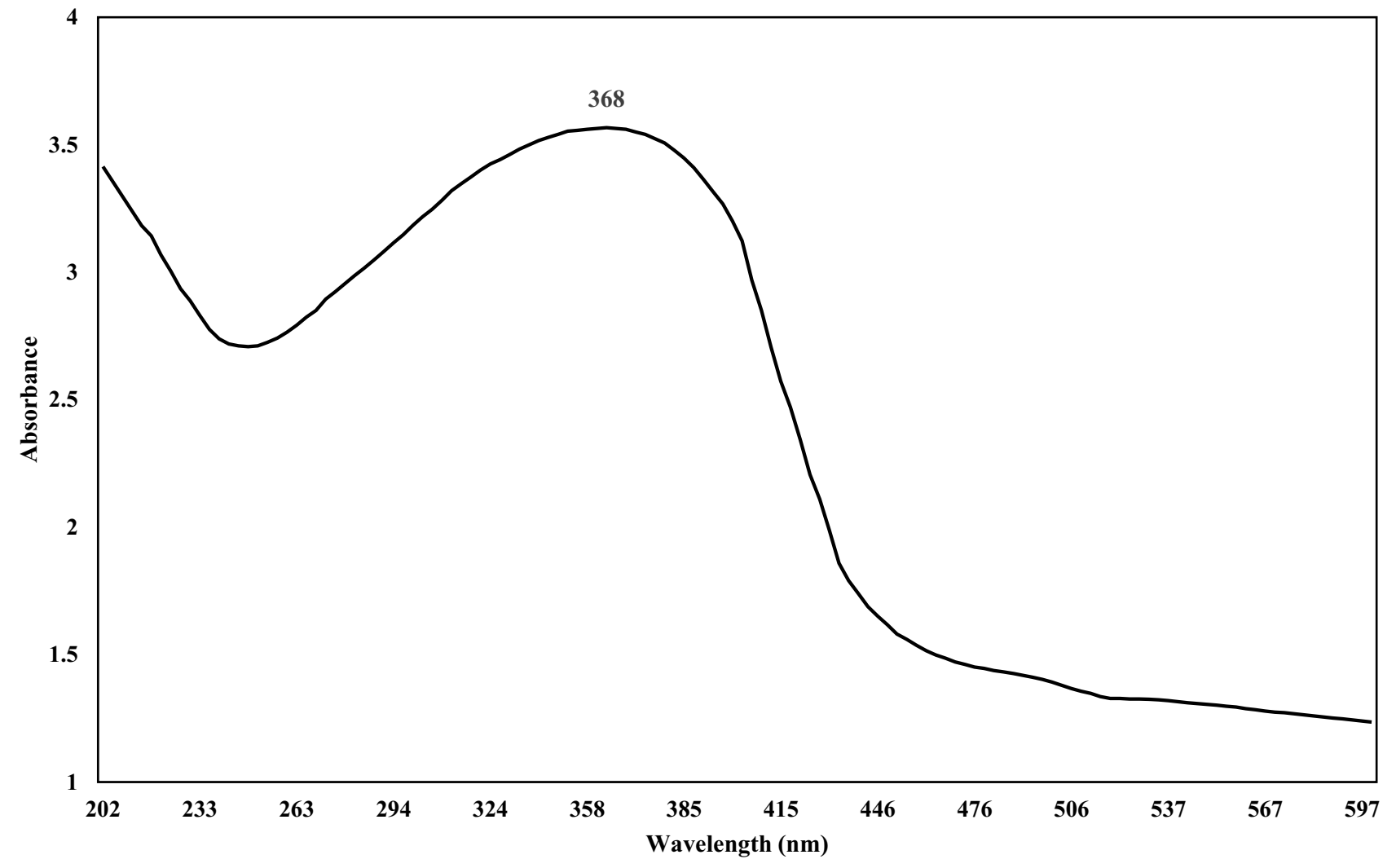

Figure 3 UV spectrum of biosynthesized $\mathrm{ZnO}$ nanoparticles. 


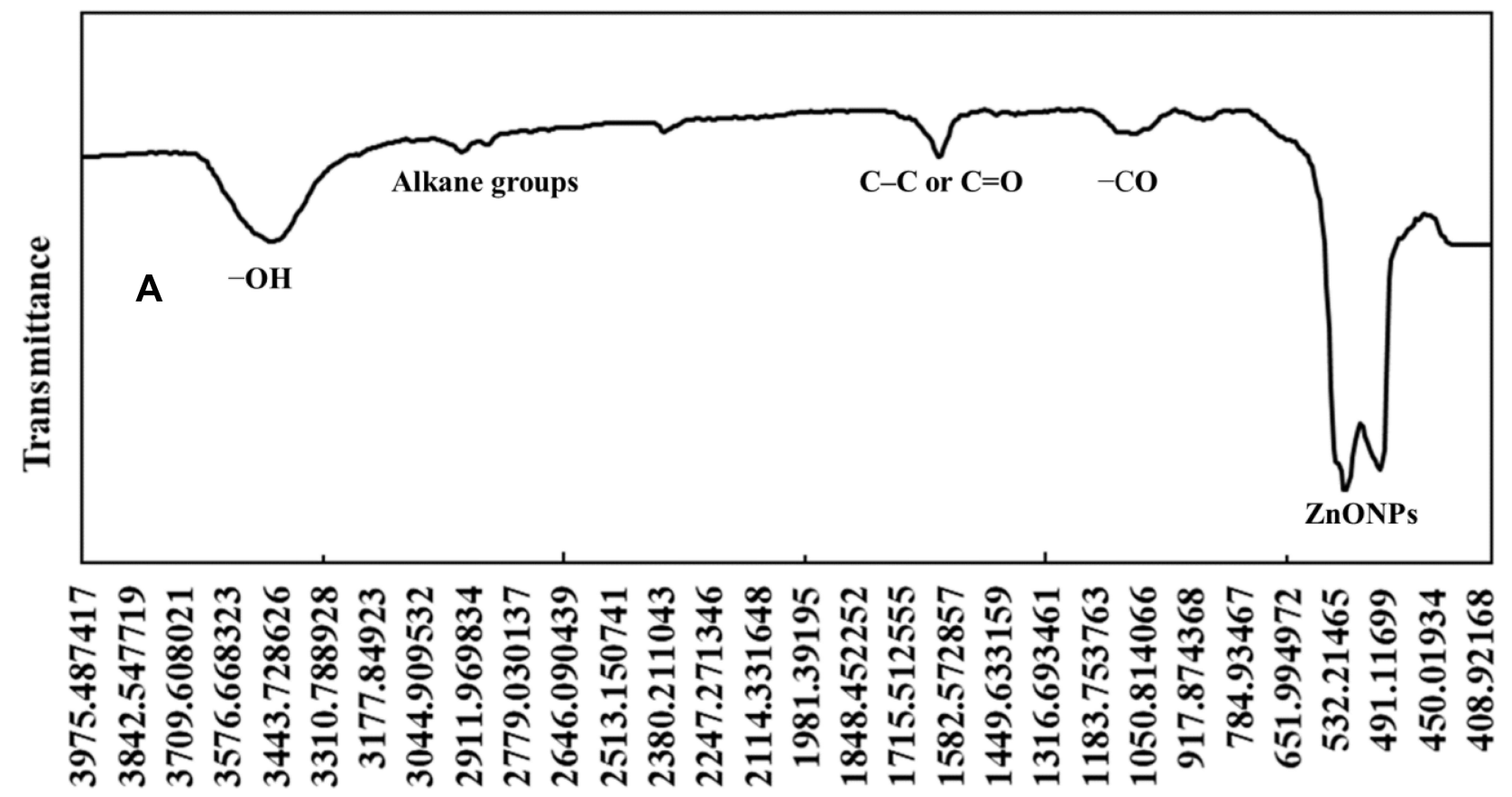

\section{Wavenumber $\mathrm{cm}^{-1}$}

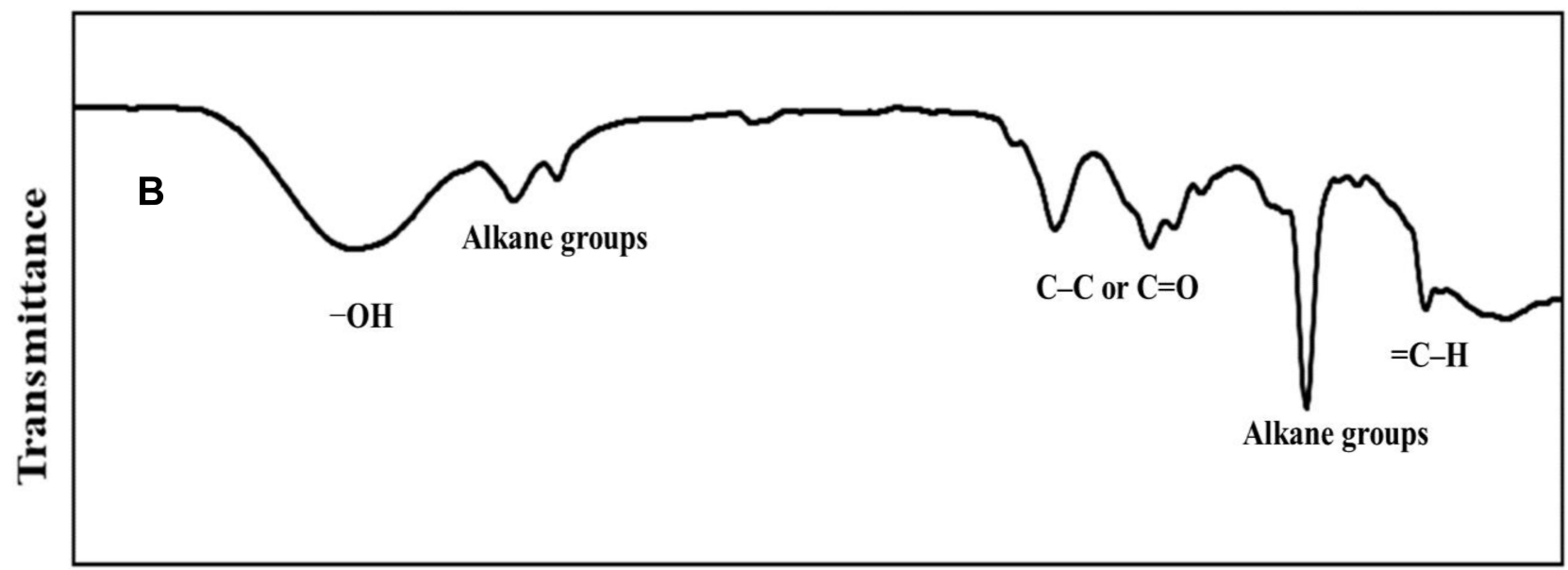

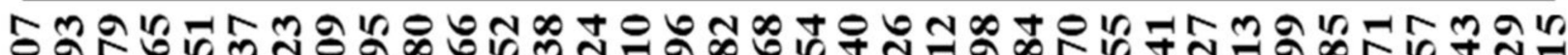
र्ते ᄀợ

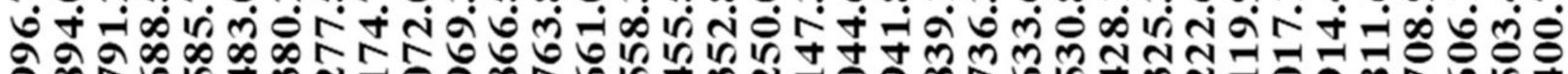
ลे

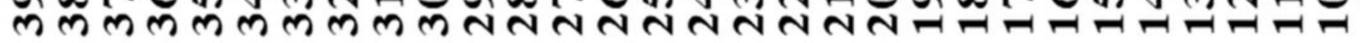

\section{Wavenumber $\mathrm{cm}^{-1}$}

Figure 4 FTIR spectra of $(\mathbf{A})$ the nanoparticles of $\mathrm{ZnO}$; $(\mathbf{B})$ the alcoholic extract of the aerial parts of $P$. indica.

(004). (202), (104), and (203), respectively. Furthermore, $\mathrm{ZnONPs}$ were considered impurity-free as there were no abnormal XRD peaks other than ZnONPs peaks. ${ }^{46,50,51}$ These peaks are reported in crystal system of hexagonal phase with a space group of $\mathrm{P} 63 \mathrm{mc}$ and reference code of (01-089-0510).

The average crystal size of ZnONPs was estimated to be $35.28 \mathrm{~nm}$, very similar to SEM and DLS results. 


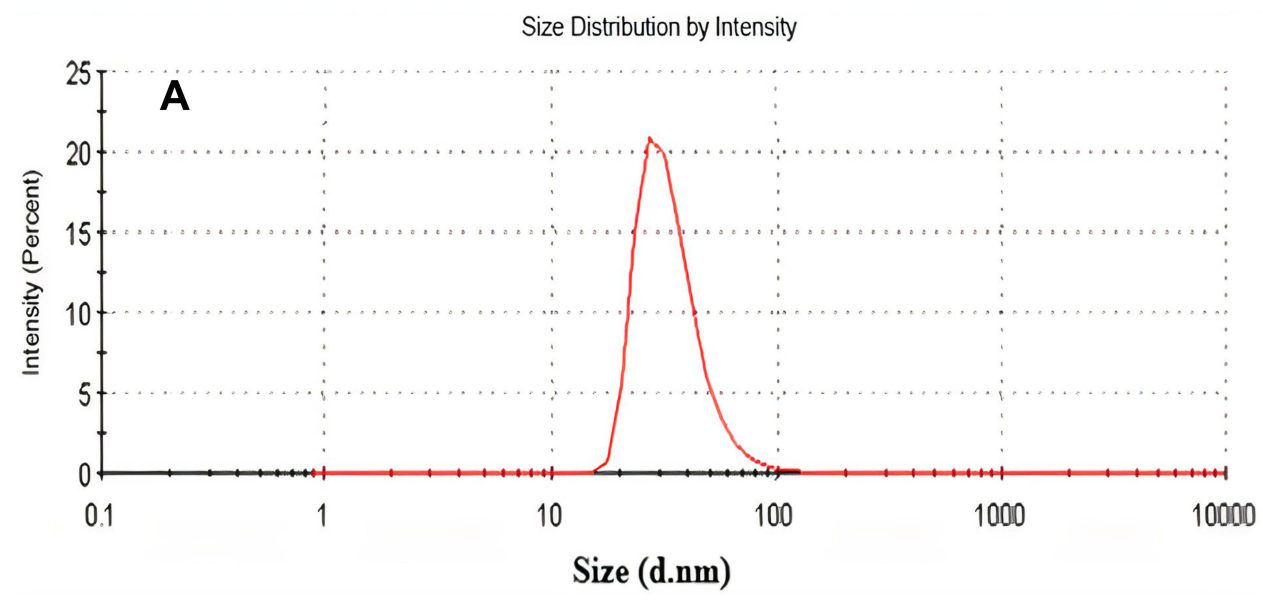

Zeta Potential Distribution

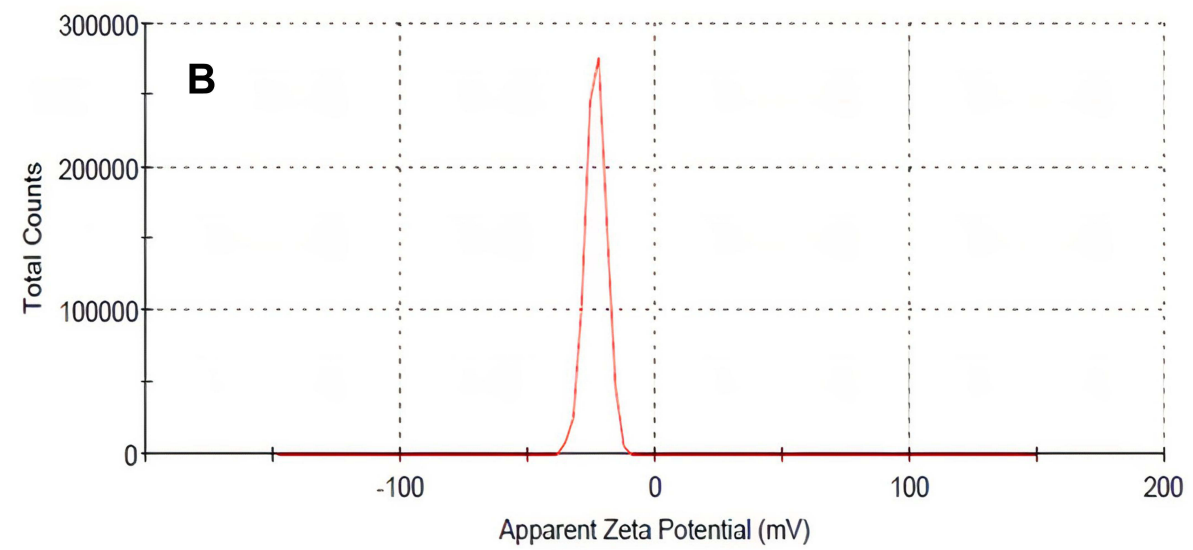

Figure 5 (A) DLS of biosynthesized zinc oxide nanoparticles; (B) zeta potential of biosynthesized zinc oxide nanoparticles.

To calculate the crystal size, Scherrer's equation was applied:

Crystal size $=(0.9 \times \lambda) /(d \cos \theta)$ where; $\Theta=2 \theta / 2, d=$ the full width at half maximum intensity of the peak (in $\operatorname{Rad}), \lambda=0.154060 \mathrm{~nm}$.

\section{Cell Viability and Antiviral Activity Results of $P$. indica $L$. Extract and ZnONPs Concentrations $(\mu \mathrm{g} / \mathrm{mL})$}

HSV-1 and HSV-2 are two types of the herpes viridae family related to orolabial and genital infections. The in vivo studies recommended that $\mathrm{Zn}$ salts can be effective against the viral infection. ${ }^{52,53}$ The first trial for employing nanoparticles as a candidates for an anti-HSV agent showed that a notable antiviral activity against HSV-1 in Vero cell line was observed in silver and gold NPs coated with mercapto ethane sulfonate. ${ }^{54,55} \mathrm{ZnO}$ micro-NPs covered with multiple nanoscopic spikes are considered a virostatic agent against HSV-1, while $\mathrm{ZnO}$ tetrapod micro-nanostructures is regarded as a prophylactic compound for the prevention of HSV-2 infection. $^{25,55}$

The screening of the antiviral activities of $P$. indica L. extract and ZnONPs obtained by in vitro cell viability revealed that both agents displayed moderate inhibition. The observed medium percentages of cell destruction on Vero cell line were $\mathrm{CC}_{50}=70.58 \pm 4.32$ and $43.96 \pm 1.39$ $\mu \mathrm{g} / \mathrm{mL}$, respectively. $P$. indica $\mathrm{L}$. and ZnONPs exhibited anti-herpetic activity, with $\mathrm{IC}_{50}=54.62 \pm 1.53$ and 23.1667 $\pm 2.2898 \mu \mathrm{g} / \mathrm{mL}$, respectively, for MOI of $0.001 \mathrm{ID}_{50}$ /cells. These results revealed that ZnONPs have better activity than the plant extract (Table 2). The antiviral activity of ZnONPs against HSV-1 could be due to direct interaction with the virus particles leading to trapping the virions followed by blocking the viral entrance into target cells. The selective inhibitory effect of $\mathrm{Zn}$ ions on viral 


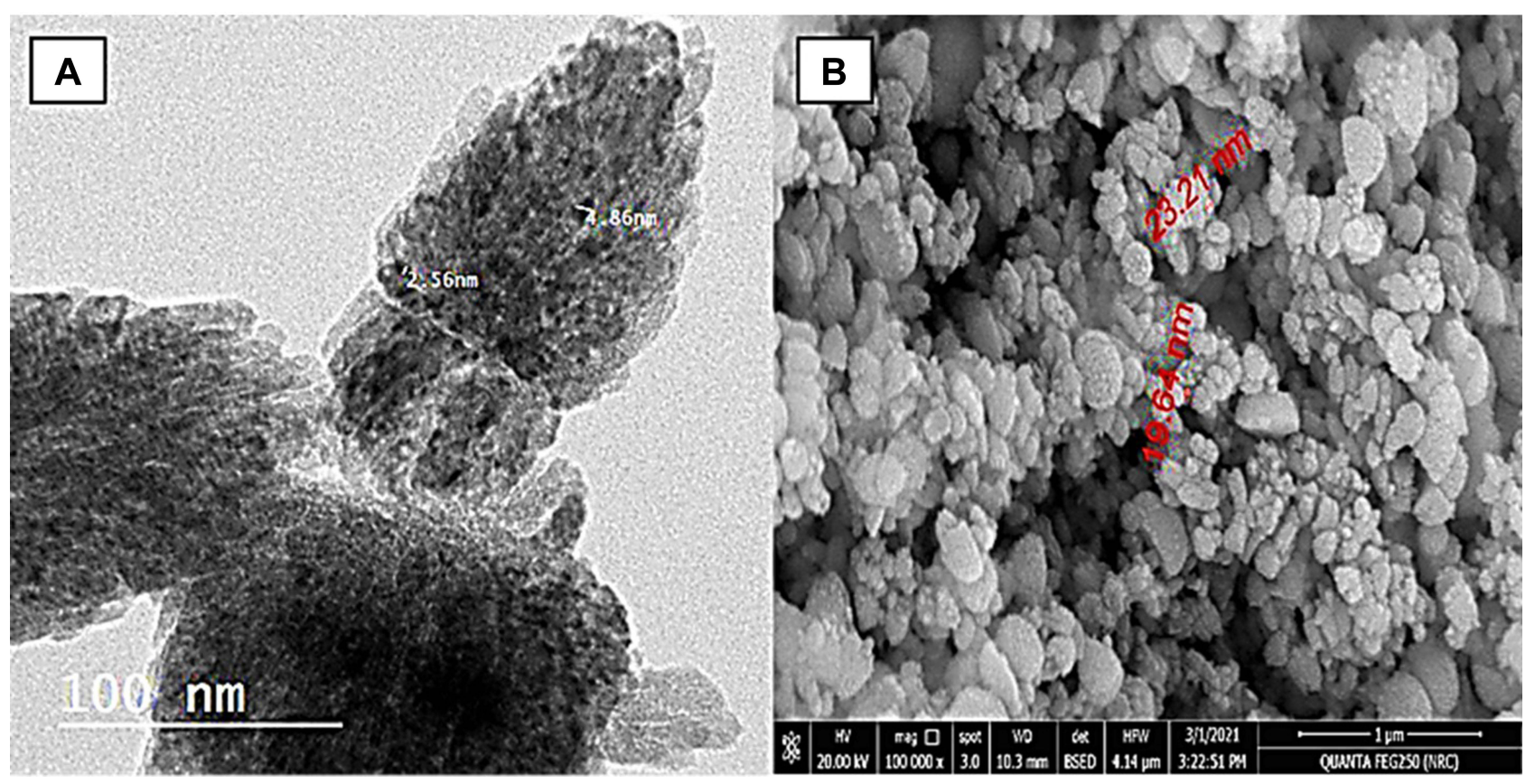

Figure 6 (A) TEM analysis of ZnONPs; (B) SEM analysis of ZnONPs.

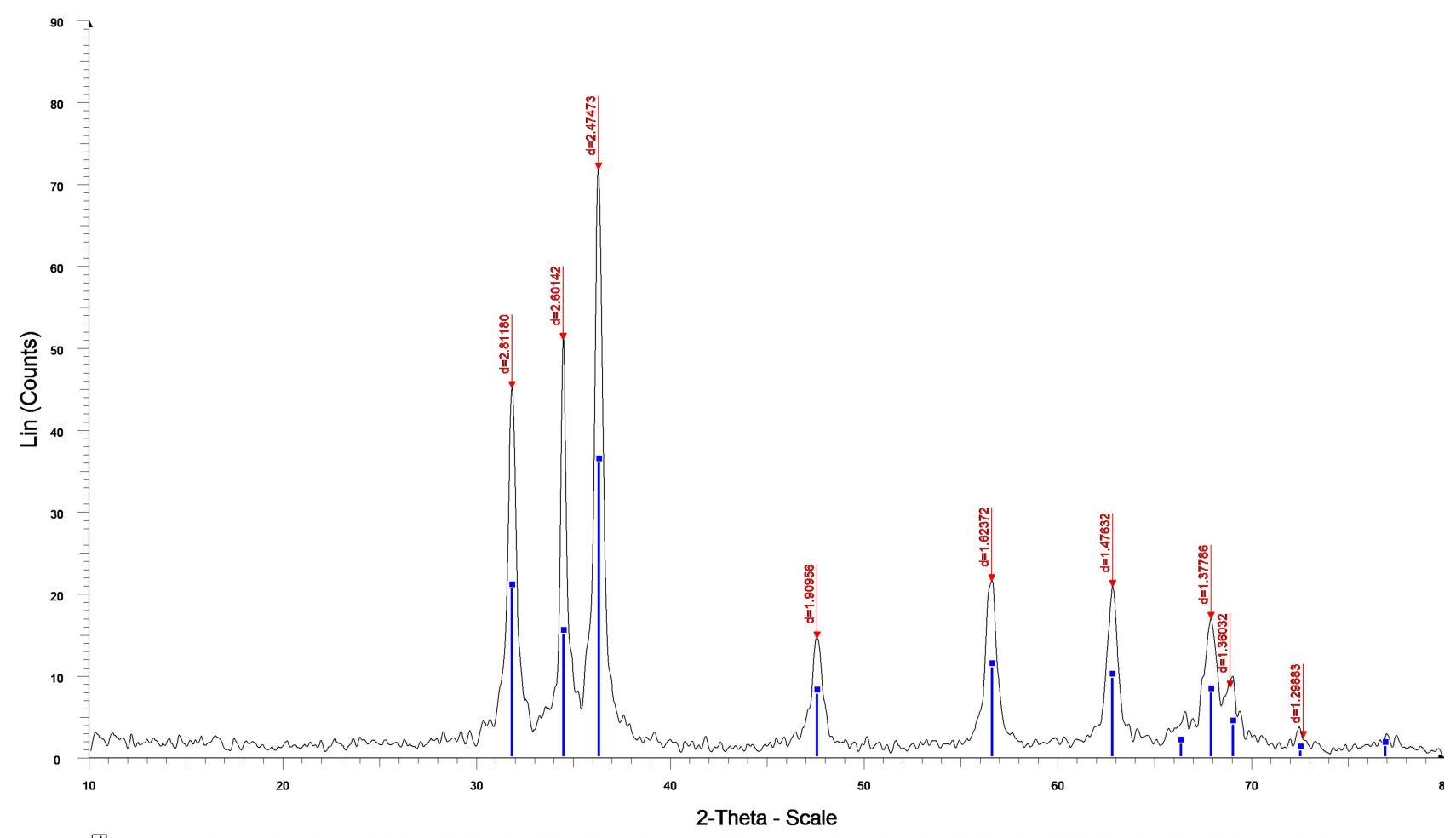

W File: PI Mina.raw - Type: 2 Th/Th locked - Start: $10.000^{\circ}$ - End: $80.000^{\circ}$ - Step: $0.020^{\circ}$ - Step time: 0.4 s - Temp.: $25^{\circ} \mathrm{C}$ (Room) - Time Started: 9 s - 2-Theta: $10.000^{\circ}$ - Theta: $5.000^{\circ}$ - Chi: $0.00^{\circ}$ - Phi: $0.000^{\circ}$ - X: $0.0 \mathrm{~mm}$ - Y: $0.0 \mathrm{~mm}$ - Z: $0.0 \mathrm{~mm}$ Operations: Smooth 0.150 | Smooth 0.150 | Strip kAlpha2 0.000 | Background 0.000,1.000 | Import
$\square$ 01-089-0510 (C) - Zinc Oxide - ZnO - Y: $50.00 \%$ - d x by: 1. - WL: 1.5406 -

Figure 7 XRD analysis of ZnONPs. 
Table 2 Anti-Herpetic (HSV-I) Activity of P. Indica Extract and ZnO Nanoparticles

\begin{tabular}{|l|l|l|l|l|l|l|}
\hline & \multicolumn{2}{|c|}{ Zovirax (Positive Control) } & \multicolumn{2}{c|}{ P. indica } & \multicolumn{2}{c|}{ ZnO Nanoparticles } \\
\hline Species & $\mathrm{CC}_{50} *$ & $\mathrm{IC} *$ & $\mathrm{CC}_{50} * @$ & $\mathrm{IC}_{50} * @$ & $\mathrm{CC}_{50} * @$ & $\mathrm{IC} *$ @ \\
Mean $\pm \mathrm{SD}$ & $>200 \pm 0.2$ & $0.5 \pm 0.4$ & $70.58 \pm 4.32$ & $54.6 \pm 1.53$ & $43.96 \pm 1.39$ & $23.17 \pm 2.29$ \\
\hline
\end{tabular}

Notes: *Values are expressed as $\mu \mathrm{g} / \mathrm{mL}$, Mean $\pm \mathrm{SD}$. ${ }^{@}$ Significantly different from positive control (Zovirax) group at $p<0.0 \mathrm{I}$.

DNA polymerase leading to inhibition of HSV replication might be an alternative mechanism. ${ }^{26}$ The antiviral activity of $P$. indica extract could be due to the active ingredients such as kaempferol that were previously found to have an antiviral property. ${ }^{56}$

In comparison to acyclovir, which provided $100 \%$ total protection against $\mathrm{HSV}-1$ at $1 \mu \mathrm{g} / \mathrm{mL}$, both $P$. indica extract and ZnONPs could be considered promising adjuvants to enhance the efficacy of HSV-1 drugs.

\section{Conclusion}

In this work, ZnONPs were successfully green synthesized by means of $P$. indica alcoholic extract. The resultant nanoparticles were characterized using DLS, zeta potential, UV-visible spectroscopy, FTIR, XRD, SEM and TEM. The antiviral activity of the ZnONPs was examined on herpes simplex virus - type 1. Our findings exposed that zinc oxide nanoparticles showed significant activity, higher than that of $P$. indica extract. This activity could be linked to its main small crystallite size $(32.58 \pm 7.98 \mathrm{~nm})$, as indicated by XRD. The highest efficacy of $P$. indica alcoholic extract and ZnONPs synthesized from this extract might contribute to the search for new agents against HSV-1 or adjuvant with the standard antiviral drug, acyclovir.

\section{Acknowledgments}

The authors acknowledge Dr. Sedki Sedik Hasan Ahmed the associate Professor of English Language and Literature, Department of Foreign Languages, Faculty of Arts, Taif University for the English editing of the article.

\section{Funding}

This research funded by the Taif University Researchers Supporting Project number (TURSP-2020/81), Taif University, Taif, Saudi Arabia.

\section{Disclosure}

The authors declare no conflicts of interest in this work.

\section{References}

1. Waseem A, Divya K. Green synthesis, characterization and anti-microbial activities of $\mathrm{ZnO}$ nanoparticles using Euphorbia hirta leaf extract. $J$ King Saud Univ Sci. 2020;32(4):2358-2364. doi:10.1016/j.jksus.2020.03.014

2. Seyyed M, Tabrizi HM, Behrouz E, Vahid J. Biosynthesis of pure zinc oxide nanoparticles using Quince seed mucilage for photocatalytic dye degradation. $J$ Alloys Compd. 2020;821:153519.

3. Vijayakumar S, Arulmozhi P, Kumar N, Sakthivel B, Prathip kumar S, Praseetha PK. Acalypha fruticose L. leaf extract mediated synthesis of $\mathrm{ZnO}$ nanoparticles: characterization and antimicrobial activities. Mater Today Proc. 2020;23:73-80.

4. Muthuvel A, Jothibas M, Manoharan C. Effect of chemically synthesis compared to biosynthesized $\mathrm{ZnO}-\mathrm{NPs}$ using Solanum nigrum leaf extract and their photocatalytic, antibacterial and in vitro antioxidant activity. $J$ Environ Chem Eng. 2020;8(2):103705. doi:10.1016/j.jece.2020.103705

5. Niranjan B, Saha S, Chakraborty M, et al. Green synthesis of zinc oxide nanoparticles using Hibiscus subdariffa leaf extract: effect of temperature on synthesis, anti-bacterial activity and anti-diabetic activity. $R S C A d v$. 2015;5(7):4993-5003.

6. Yusof HM, Mohamad R, Zaidan UH, Rahman NAA. Microbial synthesis of zinc oxide nanoparticles and their potential application as an antimicrobial agent and a feed supplement in animal industry: a review. J Anim Sci Biotechnol. 2019;10(1):57. doi:10.1186/s40104019-0368-z

7. Vidya C, Manjunatha C, Chandraprabha MN, Rajshekar M, Mal AR. Hazard free green synthesis of $\mathrm{ZnO}$ nano-photo-catalyst using Artocarpus Heterophyllus leaf extract for the degradation of Congo red dye in water treatment applications. J Environ Chem Eng. 2017;5 (4):3172-3180. doi:10.1016/j.jece.2017.05.058

8. Vidya C, Manjunatha C, Sudeep M, Ashoka S, Raj MLA. Photoassisted mineralisation of titan yellow dye using $\mathrm{ZnO}$ nanorods synthesised via environmental benign route. SN Appl Sci. 2020;2 (4):1-15. doi:10.1007/s42452-020-2537-2

9. Cai L, Liu C, Fan G, Liu C, Sun X. Preventing viral disease by ZnONPs through directly deactivating TMV and activating plant immunity in Nicotiana benthamiana. Environ Sci. 2019;6 (12):3653-3669.

10. Chaudhary A, Kumar N, Kumar R, Kumar R. Antimicrobial activity of zinc oxide nanoparticles synthesized from Aloe vera peel extract. SN Appl Sci. 2019;1(1):136. doi:10.1007/s42452-0180144-2

11. Santhoshkumar J, Kumar SV, Rajeshkumar S, Adaikalaraj G. Synthesis of zinc oxide nanoparticles using plant leaf extract against urinary tract infection pathogen. Resour Effic Technol. 2017;3 (6):459-1651. doi:10.1016/j.reffit.2017.05.001

12. Handago DT, Enyew AZ, Bedasa AG. Effects of Azadirachta indica leaf extract, capping agents, on the synthesis of pure and $\mathrm{Cu}$ doped ZnO-nanoparticles: a green approach and microbial activity. Open Chem. 2019;17(4):246-465. doi:10.1515/chem-2019-0018

13. Haque MJ, Bellah MM, Hassan MR, Rahman S. Synthesis of $\mathrm{ZnO}$ nanoparticles by two different methods \& comparison of their structural, antibacterial, photocatalytic and optical properties. Nano Express. 2020;1(1):010007. doi:10.1088/2632-959X/ab7a43 
14. El-Megharbel SM, Alsawat M, Al-Salmi FA, Hamza RZ. Utilizing of (zinc oxide nano-spray) for disinfection against "SARS-CoV-2" and testing its biological effectiveness on some biochemical parameters during (COVID-19 pandemic) - " $\mathrm{ZnO}$ nanoparticles have antiviral activity against (SARS-CoV-2)". Coatings. 2021;11(4):388. doi:10.3390/coatings 11040388

15. Attia GH, Moemen YS, Youns M, Ibrahim AM, Abdou R, El Raey MA. Antiviral zinc oxide nanoparticles mediated by hesperidin and in silico comparison study between antiviral phenolics as anti-SARS-CoV-2. Colloids Surf B Biointerfaces. 2021;203:111724. doi:10.1016/j.colsurfb.2021.111724

16. Kurian A, Sankar MA. Medicinal Plants. Horticulture science series-2. KV Peter. New Delhi: New India Publishing Agency; 2007:123-143.

17. Priyanjani HASA, Senarath RMUS, Senarath WK, Munasinghe MLAMS. Propagation, phytochemistry and pharmacology of plumbago indica-a review. ArticleGet. 2021;33:188-202.

18. Melk MM, El-Hawary SSED, Melek FR, Saleh DO, Selim NM. Cytotoxic Plumbagin-5-O- $\alpha-1-$ Rhamnopyranoside from Plumbago indica. Revista Brasileira de Farmacognosia. 2021;75:1-4. doi:10.1007/s43450-021-00185-y

19. Mallavadhani UV, Sahu G, Muralidhar J. Screening of Plumbago species for the bio-active marker plumbagin. Pharm Biol. 2002;40:508-511. doi:10.1076/phbi.40.7.508.14685

20. Hazra B, Sarkar R, Bhattacharyya S, Ghosh PK, Chel G, Dinda B. Synthesis of plumbagin derivatives and their inhibitory activities against Ehrlich ascites carcinoma in vivo and Leishmania donovani promastigotes in vitro. Phytopathol Res. 2008;16:133-137.

21. Didry N, Dubreuil L, Pinkas M. Activity of anthraquinonic and naphthoquinonic compounds on oral bacteria. Pharmazei. 1994;49:681-683.

22. Kuo PL, Hsu YL, Cho CY. Plumbagin induces G2-M arrest and autophagy by inhibiting the AKT/mammalian target of rapamycin pathway in breast cancer cells. Mol Cancer Ther. 2006;5:3209-3322. doi:10.1158/1535-7163.MCT-06-0478

23. Wiesenthal A, Hunter L, Wang S, Wickliffe J, Wilkerson M. Nanoparticles: small and mighty. Int J Dermatol. 2011;50:247-254. doi:10.1111/j.1365-4632.2010.04815.x

24. Manjunatha C, Rao PP, Bhardwaj P, Raju H, Ranganath D. New insight into the synthesis, morphological architectures and biomedical applications of elemental selenium nanostructures. Biomed Mater. 2021;16(2):022010. doi:10.1088/1748-605X/abc026

25. Mishra YK, Adelung R, Rohl C, Shukla D, Spors F, Tiwari V. Virostatic potential of micro-nano filopodia-like $\mathrm{ZnO}$ structures against herpes simplex virus-1. Antiviral Res. 2011;92:305-312.

26. Tavakoli A, Ataei-Pirkooh A, Mm Sadeghi G, et al. Polyethylene glycol-coated zinc oxide nanoparticle: an efficient nanoweapon to fight against herpes simplex virus type 1. Nanomedicine. 2018;13 (21):2675-2690. doi:10.2217/nnm-2018-0089

27. Kumar TSJ, Balavigneswaran CK, Packiaraj RM, et al. Green synthesis of silver nanoparticles by plumbago indica and its antitumor activity against dalton's lymphoma ascites model. BioNanoScience. 2013;3:394-402. doi:10.1007/s12668-013-0102-9

28. Jaryal N, Kaur H. Plumbago auriculata leaf extract-mediated AgNPs and its activities as antioxidant, anti-TB and dye degrading agents. $J$ Biomater Sci Polym Ed. 2017;28:1847-1858. doi:10.1080/ 09205063.2017.1354673

29. Govindan L, Anbazhagan S, Altemimi AB, et al. Efficacy of antimicrobial and larvicidal activities of green synthesized silver nanoparticles using leaf extract of Plumbago auriculata lam. Plants. 2020;9:1577. doi:10.3390/plants9111577

30. Roy A, Bharadvaja N. Silver nanoparticles synthesis from a pharmaceutically important medicinal plant Plumbago zeylanica. MOJ Bioequi Availa. 2017;3:46.
31. Maheswari T, Jayapriya G, Prabha N, Vennila M. Synthesis, Characterization and applications of selenium nanoparticle using Plumbago zeylanica leaves extract. Plant Cell Biotechnol Mol Biol. 2021;22:60-71.

32. Jamdade DA, Rajpali D, Joshi KA, et al. Gnidia glauca- and plumbago zeylanica-mediated synthesis of novel copper nanoparticles as promising antidiabetic agents. Adv Pharmacol Sci. 2019;2019:1-11.

33. Chopade BA, Salunke GR, Ghosh S, et al. Rapid efficient synthesis and characterization of silver, gold, and bimetallic nanoparticles from the medicinal plant Plumbago zeylanica and their application in biofilm control. Int J Nanomed. 2014;9:2635-2653. doi:10.2147/ IJN.S59834

34. Maheswari T, Vennila M. Spectroscopic investigation of green and chemically synthesized zinc oxide nanoparticles and its antimicrobial activities. IJSRR. 2018;8:3363-3377.

35. Melk MM, El-Hawary SS, Melek FR, et al. Nano zinc oxide green-synthesized from plumbago auriculata lam. alcoholic extract. Plants. 2021;10(11):2447. doi:10.3390/plants10112447

36. Attia GH, Alyami HS, Orabi MAA, Gaara AH, El Raey MA. Antimicrobial activity of silver and zinc nanoparticles mediated by eggplant green Calyx. Int $J$ Pharmacol. 2020;16:236-243. doi:10.3923/ijp.2020.236.243

37. Sayed AE-T, Salib JY, El- Kashak WA, Marty C, Bedoux G, Bourgougnon N. Antiviral effect of polyphenol rich plant extracts on herpes simplex virus type 1. Food Sci Hum Wellness. 2018;7:91-101.

38. Reed LJ, Muench HA. A simple method of estimating fifty per centendpoints. Am J Hyg. 1938;27:493-497.

39. Le Contel C, Galea P, Silvy F, Hirsch I, Chermann KC. Identification of the _2m-derived epitope responsible for neutralization of HIV isolates. Cell Pharmacol AIDS Sci. 1996;3:68-73.

40. McLaren C, Ellis MN, Hunter GA. A colorimetric assay or the measurement of the sensitivity of Herpes simplex viruses to antiviral agents. Antivir Res. 1983;3:223-234. doi:10.1016/0166-3542(83)90001-3

41. Langlois M, Allard JP, Nugier F, Aymard M. A rapid and automated colorimetric assay for evaluating in the sensitivity of Herpes simplex strains to antiviral drugs. J Biol Stand. 1986;14:201-211. doi:10.1016/0092-1157(86)90004-1

42. Harborne J. Plant polyphenols: occurrence of azalein and related pigments in flowers of Plumbago and Rhododendron species. Arch Biochem Biophys. 1962;96:171-178. doi:10.1016/0003-9861(62)90467-8

43. Srinivasan N, Rangasami C, Kannan JC. Synthesis structure and optical properties of zinc oxide nanoparticles. Int J Appl Eng Res. 2015;10:343-345.

44. Muhammad W, Ullah N, Haroon M, Abbasi BH. Optical, morphological and biological analysis of zinc oxide nanoparticles (ZnO NPs) using Papaver somniferum L. RSC Adv. 2019;9(51):29541-29548. doi:10.1039/C9RA04424H

45. Fakhari S, Jamzad M, Kabiri Fard H. Green synthesis of zinc oxide nanoparticles: a comparison. Green Chem Lett Rev. 2019;12:19-24. doi:10.1080/17518253.2018.1547925

46. Jena M, Manjunatha C, Shivaraj BW, Nagaraju G, Ashoka S, Aan MS. Optimization of parameters for maximizing photocatalytic behaviour of Zn1-xFexO nanoparticles for methyl Orange degradation using Taguchi and Grey relational analysis Approach. Mater Today Chem. 2019;12:187-199. doi:10.1016/j.mtchem.2019.01.004

47. Zak AK, Razali R, Abd Majid WH, Darroudi M. Synthesis and characterization of a narrow size distribution of zinc oxide nanoparticles. Int J Nanomedicine. 2011;6:1399. doi:10.2147/IJN.S19693

48. Yuvakkumar R, Suresh J, Saravanakumar B, Nathanael AJ, Hong SI, Rajendran V. Rambutan peels promoted biomimetic synthesis of bioinspired zinc oxide nanochains for biomedical applications. Spectrochim Acta A Mol Biomol Spectrosc. 2015;137:250-258. doi:10.1016/j.saa.2014.08.022 
49. Chai MHH, Amir N, Yahya N, Saaid IM. Characterization and colloidal stability of surface modified zinc oxide nanoparticle. J Phys Conf Ser. 2018;1123(1):012007.

50. Bigdeli F, Morsali A, Retailleau P. Syntheses and characterization of different zinc (II) oxide nano-structures from direct thermal decomposition of 1D coordination polymers. Polyhedron. 2010;29:801-806. doi:10.1016/j.poly.2009.10.027

51. Kashyout AB, Soliman HMA, Shokry Hassan H, Abousehly AM. Fabrication of $\mathrm{ZnO}$ and $\mathrm{ZnO}$ : sb nanoparticles for gas sensor applications. J Nanomater. 2010;2010:341841. doi:10.1155/2010/341841

52. Fridlender B, Chejanovsky N, Becker Y. Selective inhibition of herpes simplex virus type 1 DNA polymerase by zinc ions. Virology. 1978;84(2):551-554. doi:10.1016/0042-6822(78)90274-X

53. Shlomai J, Asher Y, Gordon YJ, Olshevsky U, Becker Y. Effect of zinc ions on the synthesis of herpes simplex virus DNA in infected BSC-1 cells. Virology. 1975;66(1):330-335. doi:10.1016/00426822(75)90204-4
54. Baram-Pinto D, Shukla S, Perkas N, Gedanken A, Sarid R. Inhibition of herpes simplex virus type 1 infection by silver nanoparticles capped with mercaptoethane sulfonate. Bioconjug Chem. 2009;20 (8):1497-1502. doi:10.1021/bc900215b

55. Baram-Pinto D, Shukla S, Gedanken A, Sarid R. Inhibition of HSV-1 attachment, entry, and cell-to-cell spread by functionalized multivalent gold nanoparticles. Small. 2010;6(9):1044-1050. doi:10.1002/ smll.200902384

56. Lyu SY, Rhim JY, Park WB. Antiherpetic activities of flavonoids againstHerpes simplex virus type 1 (HSV-1) and type 2 (HSV-2) in vitro. Arch Pharmacol Res. 2005;28:1293-1301. doi:10.1007/ BF02978215

\section{Publish your work in this journal}

The International Journal of Nanomedicine is an international, peerreviewed journal focusing on the application of nanotechnology in diagnostics, therapeutics, and drug delivery systems throughout the biomedical field. This journal is indexed on PubMed Central, MedLine, CAS, SciSearch ${ }^{\mathbb{}}$, Current Contents ${ }^{\mathbb{R}} /$ Clinical Medicine, $^{2}$
Journal Citation Reports/Science Edition, EMBase, Scopus and the Elsevier Bibliographic databases. The manuscript management system is completely online and includes a very quick and fair peer-review system, which is all easy to use. Visit http://www.dovepress.com/ testimonials.php to read real quotes from published authors. 